\title{
A novel marker of persistent left ventricular systolic dysfunction in patients with peripartum cardiomyopathy: monocyte count- to- HDL cholesterol ratio
}

Firdevs Aysenur Ekizler ${ }^{1,2^{*}}$ (D) and Serkan Cay ${ }^{1,2}$

\begin{abstract}
Background: Peripartum cardiomyopathy (PPCM) is a rare but potentially life-threatening complication of pregnancy. There is limited data regarding the predictors of persistent left ventricular (LV) systolic dysfunction. Recently, monocyteto-high density lipoprotein (HDL) cholesterol ratio (MHR) has emerged as a novel indicator of inflammation and oxidative stress. We aimed to assess the predictive value of MHR on LV recovery in patients with PPCM.

Methods: A total of 64 patients with PPCM who admitted to our tertiary reference hospital between 2009 and 2017 were retrospectively analyzed in this study. Demographic and clinical data, laboratory parameters and echocardiographic findings were recorded. The duration of follow-up was at least 12 months after diagnosis for all participants. Recovery of LV systolic function was defined as the presence of LV ejection fraction (LV EF) $>45 \%$. Univariate analysis was used to determine the significant predictors of persistent LV systolic dysfunction (non-recovery). A receiver operating characteristic (ROC) curve was used to establish the cut-off values for predictors.

Results: The mean follow-up duration was $72.1 \pm 5.5$ months. Of the 64 patients, 35 (55\%) had persistent LVSD at their last follow-up while 29 (45\%) showed LV EF improvement. The baseline MHR levels were significantly higher in the nonrecovery group $(P<0.001)$. In univariate analysis, increased MHR levels (odds ratio:1.17; 95\% confidence interval, 1.01-1.35; $P<0.001)$ significantly predicted LV non-recovery. Using a cut-off level of 9.73, MHR predicted persistent LV systolic dysfunction with a sensitivity of $89 \%$ and specificity of 79\%. Besides, lower baseline LVEF increased WBC and CRP levels were identified as predictors of LV non-recovery.
\end{abstract}

Conclusions: Our data firstly indicated that elevated MHR was a significant predictor of persistent LV systolic dysfunction in PPCM. The MHR might contribute to determining high-risk patients with PPCM.

Keywords: Left ventricular recovery, Marker, Monocyte-to-HDL cholesterol ratio, Peripartum cardiomyopathy

\section{Background}

Peripartum cardiomyopathy (PPCM) is an uncommon but potentially life-threatening complication of pregnancy [1]. It is defined as, an occurrence of unexplained heart failure with reduced $\mathrm{EF}$, usually $<45 \%$, presenting toward the end of the pregnancy or in the first months postpartum in previously healthy women, where no other cause of heart failure is found [2]. PPCM is endemic in parts of Africa, but

\footnotetext{
* Correspondence: firdevs_bsk@hotmail.com

${ }^{1}$ Department of Cardiology, Turkiye Yuksek Ihtisas Training and Research Hospital, Ankara, Turkey

²Türkiye Yüksek Ihtisas Hastanesi Kardiyoloji Klinigi, Ankara 06100, Turkey
}

the actual incidence is unknown [3]. The exact pathophysiological mechanism that leads to PPCM is an unknown but genetic basis, viral myocarditis, abnormal immune or hemodynamic response to pregnancy, nutrient deficiency, increased oxidative stress and inflammation have all been proposed [2,4-7]. The clinical course is markedly heterogeneous. PPCM might lead to progressive heart failure, thromboembolic complications, malignant arrhythmias, and even death [8]. On the other side of the spectrum, PPCM is associated with high likelihood of LV recovery (up to $41 \%$ depending on the race, study size and follow-up period) $[1,9,10]$. The differences in the clinical

(c) The Author(s). 2019 Open Access This article is distributed under the terms of the Creative Commons Attribution 4.0 International License (http://creativecommons.org/licenses/by/4.0/), which permits unrestricted use, distribution, and reproduction in any medium, provided you give appropriate credit to the original author(s) and the source, provide a link to the Creative Commons license, and indicate if changes were made. The Creative Commons Public Domain Dedication waiver (http://creativecommons.org/publicdomain/zero/1.0/) applies to the data made available in this article, unless otherwise stated. 
course have induced clinical researchers to identify baseline predictors of outcome. Predictors of persistent left ventricular systolic dysfunction (LVSD) are inconsistently defined and include lower baseline LV ejection fraction (LV EF), late diagnosis, older age, black race and elevated plasma markers of inflammation $[1,2,9]$. Therefore, the ability to identify early predictors of prognosis in patients diagnosed with PPCM is very important in risk stratification, preventing complications and improving outcomes.

Considering the possible role of oxidative stress and inflammation in the initiation and progression of PPCM, various inflammatory biomarkers including $\mathrm{C}$-reactive protein (CRP), TNF-alpha and interleukin- 6 have been studied and demonstrated to be associated with this unique form of heart failure. Recently, monocyte-to-high density lipoprotein (HDL) cholesterol ratio (MHR) has emerged as a novel and widely available inflammation and oxidative stress-based marker. In several studies, MHR has been reported as a significant prognostic marker in various cardiovascular diseases $[5,6,8]$. However, the prognostic value of MHR in patients with PPCM has not yet been described. Thus, in the current study, we sought to investigate the predictive value of baseline MHR on patients with PPCM.

\section{Methods}

\section{Study population}

A total of 64 consecutive patients diagnosed with PPCM in our tertiary reference center between April 2009 and May 2017 were included in this retrospective analysis. PPCM was defined as an occurrence of unexplained heart failure with LVEF $<45 \%$, presenting toward the end of pregnancy or in the first months after delivery in previously healthy women [1]. All women were at least 18 years of age. Exclusion criteria were having a history of cardiomyopathy, severe organic valvular heart disease, significant coronary heart disease ( $\geq 50 \%$ luminal diameter stenosis in at least 1 major coronary arteries and their branches), clinical conditions other than cardiomyopathy that could increase plasma levels of inflammatory markers such as active cancer, active infection, chronic inflammatory disease, chronic antihyperlipidemic treatment, and patients without a recorded measurement of admission laboratory parameters were excluded from this study. Data regarding clinical and demographic features and laboratory parameters were obtained from the patients' medical records. The follow-up duration was at least 12 months after diagnosis of PPCM for all patients. Standard, 2-dimensional and Doppler echocardiographic measurements were performed in all women at the time of diagnosis and the last follow-up visit. LVEF was measured using the Modified Simpson rule. Recovery of LV systolic function was accepted as the presence of LVEF $>45 \%$, whereas non-recovery (persistent left ventricular systolic dysfunction) was defined as the presence of LVEF $\leq 45 \%$ at last follow-up visit.

Fasting venous blood samples were collected at baseline in pre-cooled EDTA tubes for the hematological test and dry tubes for biochemical analyses. The HDL-C concentration was determined by selective solubilization method (Determiner L HDL, Kyowa Medex, Tokyo, Japan). WBC counts were measured using an automated hematology analyzer XE-1200 (Sysmex, Kobe, Japan). Baseline MHR was calculated by dividing the absolute count of the monocytes by the complete counts of the HDL-C. The local ethics committee approved the study protocol.

\section{Statistical analysis}

Data were analyzed using the SPSS 20.0 Statistical Package Program for Windows (SPSS, Inc., IL, USA). Continuous variables were reported as mean \pm SD and median with interquartile ranges as appropriate and categorical variables were expressed as the number of patients and percentages. The Shapiro-Wilk test was used to test the normality of distribution. The comparisons between groups were evaluated by using Student's t-test for normally distributed variables and Mann-Whitney $U$ test for variables without normal distribution. The Chisquare or Fisher's Exact test was used to compare categorical variables as appropriate. A univariate Logistic regression analysis was used to assess the capability of the individual variables to predict persistent LVSD. We did not use multivariate analysis as the small sample size may limit the power of the statistical test in revealing independent predictors. The ROC curve analysis was used to establish an optimum cut-off level of admission MHR values to predict persistent LVSD. A $p$-value $<0.05$ (using a two-sided test) was considered significant.

\section{Results}

Sixty-four patients were identified with the diagnosis of PPCM. The mean age at diagnosis was $29.2 \pm 6.0$ years. For the entire study population, $15.6 \%$ had a history of chronic or gestational hypertension, $10.9 \%$ had a family history of dilated cardiomyopathy, $4.7 \%$ were diabetic, $17.2 \%$ were dyslipidemic, and $3.1 \%$ had a history of CAD. The percentage of women in each New York Heart Association functional class (I to IV) at admission was 8.6, $62.1,25.9,3.7 \%$, respectively. The mean follow-up duration was $72.1 \pm 5.5$ months. The majority of the women were treated with optimal therapy for heart failure (beta blockers and angiotensin-converting enzyme inhibitors (ACEI)/angiotensin receptor blockers (ARBs)). There was no difference in the use of beta-blockers and ACEI/ ARBs in patients with and without recovery of LV function. None of the PPCM patients received bromocriptine.

There were 29 (45.3\%) women who had LV recovery (recovery group), while 35 (54.7\%) women had persistent 
LV systolic dysfunction (non-recovery group) at their last follow-up. Baseline clinical and laboratory characteristics of patients with and without a recovery in LVEF are shown in Table 1 . Five women among the recovery group received an intracardiac defibrillator (ICD) early in their follow-up $(n=5 / 29,17 \%)$, while $15 \quad(n=15 / 35,43 \%)$ devices were present in the non-recovery group. ICD was implanted for primary prevention in 19 women and secondary prevention in one woman. There were appropriate ICD shocks for VT in four (11.4\%) patients with persistent LVSD and one (3.4\%) patient with LV recovery. In the non-recovery group, there were five deaths during

Table 1 Baseline clinical and laboratory characteristics of patients with and without recovery in LVEF

\begin{tabular}{|c|c|c|c|}
\hline Characteristic & $\begin{array}{l}\text { Nonrecovery Group } \\
(n=35)\end{array}$ & $\begin{array}{l}\text { Recovery Group } \\
(n=29)\end{array}$ & $P$ value \\
\hline Age at diagnosis (years) (SD) & $29.8 \pm 6,0$ & $28.5 \pm 6,0$ & 0.417 \\
\hline Hypertension, n (\%) & $5(14.3)$ & $5(17.2)$ & 0.746 \\
\hline Dyslipidemia, n (\%) & $8(23.5)$ & $3(10.3)$ & 0.169 \\
\hline CAD, n (\%) & $0(0)$ & $2(7.1)$ & 0.124 \\
\hline Diabetes, n (\%) & $3(9.1)$ & $0(0)$ & 0.102 \\
\hline COPD, n (\%) & $2(6.3)$ & $0(0)$ & 0.178 \\
\hline Family history, (\%) & $6(18.8)$ & $1(3.6)$ & 0.109 \\
\hline ICD, n (\%) & $15(42.8)$ & $5(17.2)$ & 0.043 \\
\hline True ICD therapy, n (\%) & $4(11.4)$ & $1(3.4)$ & 0.236 \\
\hline ACEI / ARB, n (\%) & $29(82.9)$ & $24(82.8)$ & 0.992 \\
\hline B-blockers, n (\%) & $28(80)$ & $23(79.3)$ & 0.946 \\
\hline Digoxin, n (\%) & $11(31.4)$ & $7(24.1)$ & 0.518 \\
\hline Heart rate (bpm) & $82.3 \pm 14.1$ & $81.4 \pm 13.9$ & 0.793 \\
\hline Systolic blood pressure (mmHg) & $120.1 \pm 13.4$ & $121.7 \pm 11.9$ & 0.610 \\
\hline Diastolic blood pressure $(\mathrm{mmHg})$ & $77.4 \pm 5.9$ & $77.6 \pm 5.6$ & 0.843 \\
\hline Body- mass index $\left(\mathrm{kg} / \mathrm{m}^{2}\right)$ & $24.0 \pm 4.7$ & $25.0 \pm 4.7$ & 0.377 \\
\hline Baseline LV EF ${ }^{a}(\%)$ & $29.0(21.0-35.0)$ & $36.0(33.5-39.5)$ & $<0.001$ \\
\hline Uric acid ${ }^{a}(\mathrm{mg} / \mathrm{dl})$ & $6.8(4.9-8.8)$ & $5.6(4.8-6.8)$ & 0.076 \\
\hline Urea $^{a}(\mathrm{mg} / \mathrm{dl})$ & $30.0(20.0-38.0)$ & 23.5(19.0-27.7) & 0.053 \\
\hline Creatinine ${ }^{a}(\mathrm{mg} / \mathrm{dl})$ & $0.74(0.63-0.94)$ & $0.71(0.59-0.82)$ & 0.131 \\
\hline $\mathrm{GFR}(\mathrm{SD})\left(\mathrm{mL} / \mathrm{m}^{2}\right)$ & $94.0 \pm 35.5$ & $102.1 \pm 29.9$ & 0.455 \\
\hline Total cholesterol ${ }^{\mathrm{a}}(\mathrm{mg} / \mathrm{dl})$ & $171(132-212)$ & 159(144-184) & 0.278 \\
\hline Triglyceride ${ }^{a}(\mathrm{mg} / \mathrm{dl})$ & 136.0(88.0-180.0) & $97.0(84.0-128.0)$ & 0.049 \\
\hline LDL-C ${ }^{a}(\mathrm{mg} / \mathrm{dl})$ & 102.0(74.0-13.0) & $85.0(73.5-112.5)$ & 0.200 \\
\hline $\mathrm{HDL}-\mathrm{C}(\mathrm{mg} / \mathrm{dl})(\mathrm{SD})$ & $39.9 \pm 14.6$ & $52.0 \pm 13.2$ & 0.001 \\
\hline Albumin (mg/dl) (SD) & $4.0 \pm 0.6$ & $4.1 \pm 0.6$ & 0.390 \\
\hline $\mathrm{CRP}^{\mathrm{a}}(\mathrm{mg} / \mathrm{dl})$ & $6.2(2.4-19)$ & $2.1(0.9-3.3)$ & $<0.001$ \\
\hline Hemoglobin (g/dl) (SD) & $12.5 \pm 1.7$ & $12.8 \pm 1.9$ & 0.53 \\
\hline $\mathrm{WBC}^{\mathrm{a}}\left(\times 10^{3} \mu \mathrm{L}\right)$ & $8.3(7.2-10.5)$ & $7.5(5.8-8.5)$ & 0.021 \\
\hline Neutrophil ${ }^{a}\left(\times 10^{3} \mu \mathrm{L}\right)$ & $5.0(4.1-6.6)$ & $4.8(3.7-5.3)$ & 0.113 \\
\hline Lymphocyte $^{\mathrm{a}}\left(\times 10^{3} \mu \mathrm{L}\right)$ & $2.4(1.8-2.9)$ & $2.0(1.4-2.6)$ & 0.084 \\
\hline Monocyte $\left(\times 10^{3} \mu \mathrm{L}\right)(\mathrm{SD})$ & $0.63 \pm 0.18$ & $0.47 \pm 0.14$ & $<0.001$ \\
\hline Monocyte / HDL ratio ${ }^{a}$ & 15.5(10.8-28.5) & $8.8(6.4-13.8)$ & $<0.001$ \\
\hline MHR $>9.73, \mathrm{n}(\%)$ & 31 (88.6) & $11(37.9)$ & $<0.001$ \\
\hline
\end{tabular}

Bold data displays statisticially significant difference $(p<0.05)$

$A C E I$ angiotensin-convertingenzyme inhibitör, $A R B$ angiotensin receptor blocker, $C A D$ coronary artery disease, COPD chronic obstructive pulmonary disease, CRP Creactive protein, GFR glomeruler filtration rate, $H D L$-C high-density lipoprotein cholesterol, ICD intracardiac defibrillator, $L D L-C$ low-density lipoprotein cholesterol, LVEF left ventricular ejection fration,MHR monocyte to HDL cholesterol ratio, $S D$ standart deviation, WBC white blood cell

${ }^{a}$ Comparison was made using Mann-Whitney $U$ test at $P<0.05$, and these values were described by median with inter-quartile range (25th and 75 th percentile) 
follow-up (four from progressive LV systolic dysfunction and one from stroke). During the follow-up period; one left ventricular assist device implantation, one heart transplantation and six embolic events (four among non-recovery group and two among recovery group) occurred in patients. There was no significant difference between recovery and non-recovery groups concerning to age and co-morbidities such as; hypertension, dyslipidemia, diabetes mellitus, chronic obstructive pulmonary disease (COPD), coronary artery disease (CAD). Besides laboratory, parameters were similar between the two groups (Table 1). However, the LV non-recovery group had significantly higher plasma monocyte level, WBC count, HDL-C, CRP, and MHR. The comparison between recovery and non-recovery group according to admission MHR values is shown in Fig. 1. Patients with more severe LV dysfunction at study entry had significantly lower LVEFs at the last follow-up visit.

To examine the parameters associated with persistent LV systolic dysfunction, we designed univariate logistic regression analysis. Univariate analysis demonstrated that initial LV EF, WBC count, HDL, monocyte count, CRP, and MHR were associated with persistent LV systolic dysfunction (Table 2).
The ROC curve analysis explored the discriminatory capability of admission MHR for the LV recovery. Area under the curve was 0.861 (95\% CI: 0.768-0.954; $P<$ 0.001). Using a cutoff level of 9.73, MHR predicted persistent LV systolic dysfunction with a sensitivity of $89 \%$ and specificity of $79 \%$ (Fig. 2).

\section{Discussion}

In the present study, it was found that admission MHR values were significantly higher in the non-recovery group compared with the recovery group. Higher baseline CRP and WBC levels and lower baseline LV EF in addition to higher baseline MHR were significant predictors of LV recovery. To our knowledge, our study is the first in the literature investigating the possible relation between MHR and PPCM up till now.

The outcomes of PPCM differs widely. PPCM is a particular type of cardiomyopathy with the greatest possibility of myocardial recovery. It was shown that many patients with PPCM recover LV function partially or entirely, nonetheless failure to recover can be associated with significant adverse events and death $[1,11,12]$. Unfortunately, there are no accurate and exact predictors of whether or not myocardial recovery will occur. The attempts of clinical researchers to identify baseline

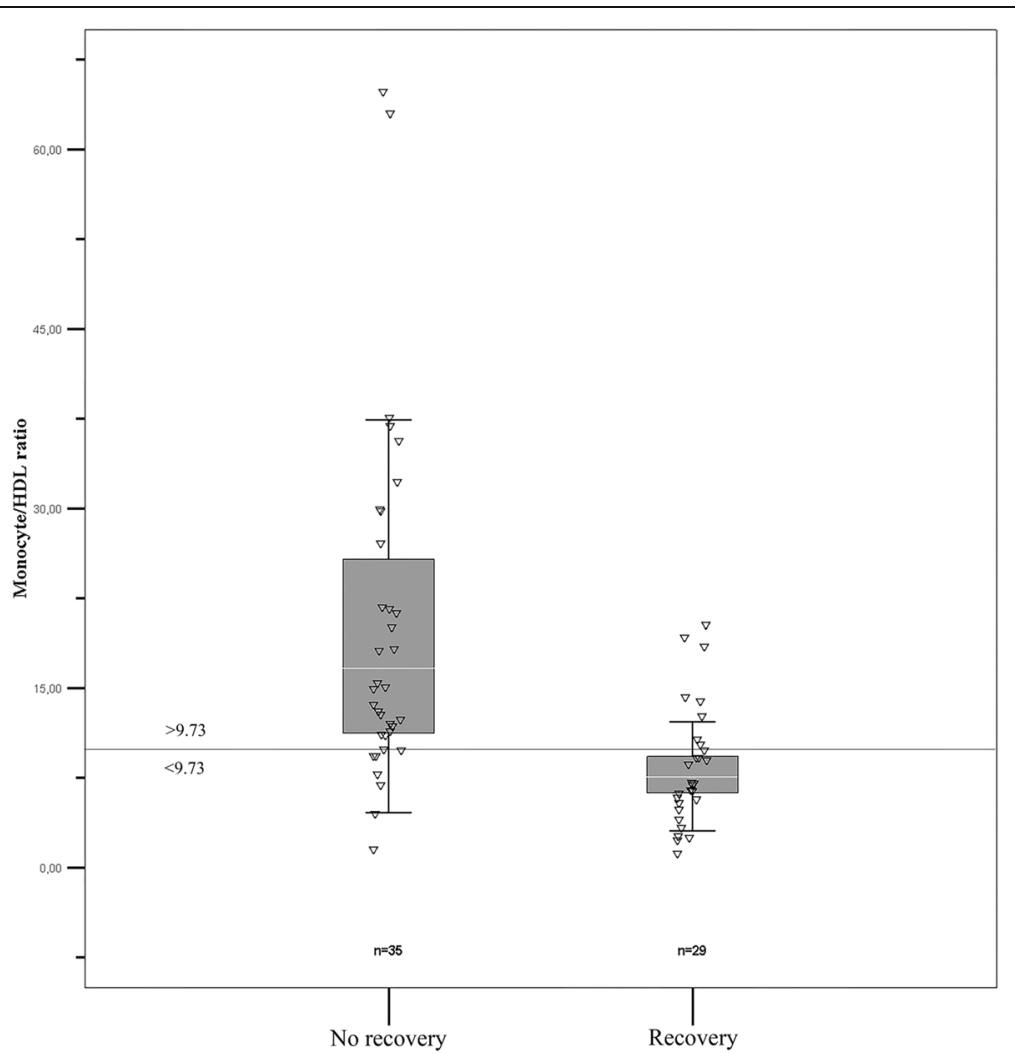

Fig. 1 Monocyte to-HDL-cholesterol ratio according to left ventricular recovery. Monocyte to -HDL-cholesterol ratio was significantly higher in nonrecovery group. $\mathrm{HDL}$, high density cholesterol 
Table 2 Univariate logistic regression analyses for prediction of nonrecovery

\begin{tabular}{llll}
\hline Variable & OR & $95 \% \mathrm{Cl}$ & $P$ value \\
\hline Age & 1.077 & $0.918-1.265$ & 0.362 \\
Hypertension & 1.380 & $0.320-5.957$ & 0.666 \\
Dyslipidemia & 2.568 & $0.613-10.752$ & 0.197 \\
Family history of PPCM & 5.793 & $0.655-51.235$ & 0.114 \\
Baseline LVEF & 0.831 & $0.749-0.921$ & $<\mathbf{0 . 0 0 1}$ \\
ACEl /ARB & 1.007 & $0.273-3.711$ & 0.992 \\
B-blockers & 1.043 & $0.307-3.541$ & 0.946 \\
Digoxin & 1.440 & $0.475-4.372$ & 0.519 \\
Heart rate & 1.005 & $0.969-1.042$ & 0.789 \\
Systolic blood pressure & 0.990 & $0.952-1.029$ & 0.604 \\
Diastolic blood pressure & 0.991 & $0.909-1.080$ & 0.840 \\
Body- mass index & 0.952 & $0.854-1.060$ & 0.371 \\
HDL-C & 0.938 & $0.899-0.979$ & $\mathbf{0 . 0 0 3}$ \\
CRP & 1.247 & $1.061-1.465$ & $\mathbf{0 . 0 0 7}$ \\
WBC & 1.407 & $1.077-1.839$ & $\mathbf{0 . 0 1 2}$ \\
Monocyte & 1.976 & $1.309-2.983$ & $\mathbf{0 . 0 0 1}$ \\
Monocyte/HDL ratio & 1.198 & $1.069-1.343$ & $\mathbf{0 . 0 0 2}$ \\
Monocyte/HDL ratio $<9.73$ & 0.079 & $0.022-0.285$ & $<\mathbf{0 . 0 0 1}$ \\
\hline
\end{tabular}

Bold data displays statisticially significant difference $(p<0.05)$ $A C E I$ angiotensin-convertingenzyme inhibitör, $A R B$ angiotensin receptor blocker, $\mathrm{Cl}$ confidence interval, $C R P C$ reactive proein, $H D L-C$ high density lipoprotein cholesterol, LVEF left ventricular ejection fraction, $O R$ odds ratio, PPCM peripartum cardiomyophaty, WBC White blood cell

predictors of poor outcomes in women with PPCM has culminated in the establishing of several predictors with moderate and inconsistent associations with prognosis.

Several studies have shown a correlation between a more depressed LV EF at initial diagnosis and a worse outcome in these patients $[13,14]$. In addition, previous studies have reported a relation between an increased LVEDD, increased LVESD (left ventricular end-systolic diameter) on the initial echocardiogram, lower systolic blood pressure, higher resting heart rate and persistent LV dysfunction [15-17]. In our study, only lower baseline LV EF from echocardiographic findings was found a significant predictor of persistent LV dysfunction.

The exact pathophysiological mechanism that leads to PPCM is unknown, but increased oxidative stress and inflammation have been proposed in the pathogenesis of manifest cardiomyopathy. Recently, it was postulated that an oxidative stress- cathepsin D$16-\mathrm{kDa}$ prolactin cascade is related to the pathophysiological mechanism of PPCM. During peri/postpartum period, enhanced oxidative stress that triggers the proteolytic cleavage of the prolactin into a potent anti-angiogenic, pro-apoptotic and proinflammatory $16-\mathrm{kDa}$ prolactin fragment seems to play a central role in decreasing cardiomyocyte metabolism [18].
Inflammation can be measured using a variety of hematological and biochemical markers. In a recent study, Sarojini et al. found that the baseline IL-6, CRP, and TNF-alpha were relevant to the mortality in PPCM patients [19]. In another study, Gleicher et al. have demonstrated evidence of an inflammatory process characterized by cytokine imbalance associated with PPCM [20]. Sliwa et al. found that plasma marker of apoptosis (Fas/Apo-1) was relevant to the clinical course of this disease [21]. However, in these studies, the role of MHR, as an easily accessible new inflammation-based marker has not been assessed in predicting LV recovery. It is widely accepted that monocyte activation is strongly implicated in chronic inflammation and almost every aspect of cardiovascular diseases [22, 23]. Under certain stimuli, circulating monocytes transform into macrophages. Monocytes and monocyte-derived macrophages can trigger an inflammatory cascade involving the production of cytokines [24]. It has been suggested that such cytokines migrate to the myocardium and adhere to the endothelial wall. Therefore, infiltration of the myocardium eventually results in fibrosis and $\operatorname{HF}[25,26]$.

On the other hand, high-density lipoprotein cholesterol (HDL) molecules counteract these pro-inflammatory and pro-oxidant effects of monocytes by impeding the migration -activation of monocytes and proliferation-differentiation of the progenitor cells of monocytes [27-29]. Thus, monocytes display pro-inflammatory and pro-oxidant effects, but HDL acts as a reversal factor during those processes. Hence, it is reasonable to combine these two parameters into a single ratio as oxidative stress and inflammationbased marker. Recently, MHR has emerged as a new and widely available cardiovascular prognostic marker. Its association of cardiovascular diseases (CVDs) has been examined in a few studies. The first study of Kanbay et al. reported that higher MHR has been associated with worse cardiovascular outcomes in patients with chronic kidney disease [30]. Another study suggested that, in patients with acute ST-segment elevation myocardial infarction (STEMI), the admission MHR values were independently correlated with in-hospital major adverse cardiovascular events (MACEs) and stent thrombosis as well as mortality [31]. In two different studies evaluating MHR in patients with stable or unstable angina pectoris who were undergone percutaneous coronary intervention with bare-metal stent implantation, investigators found a high level of admission MHR values were related with in-stent restenosis [32, 33]. Similarly, Kundi et al. [34] demonstrated that MHR was significantly higher in patients with coronary artery ectasia (CAE) and associated with the severity of CAE. Besides that, in a new study, MHR was found to be associated with CVD and the severity of obstructive sleep apnea syndrome (OSAS) [35].

All these findings show the importance of MHR in inflammation which has an essential role in the development 


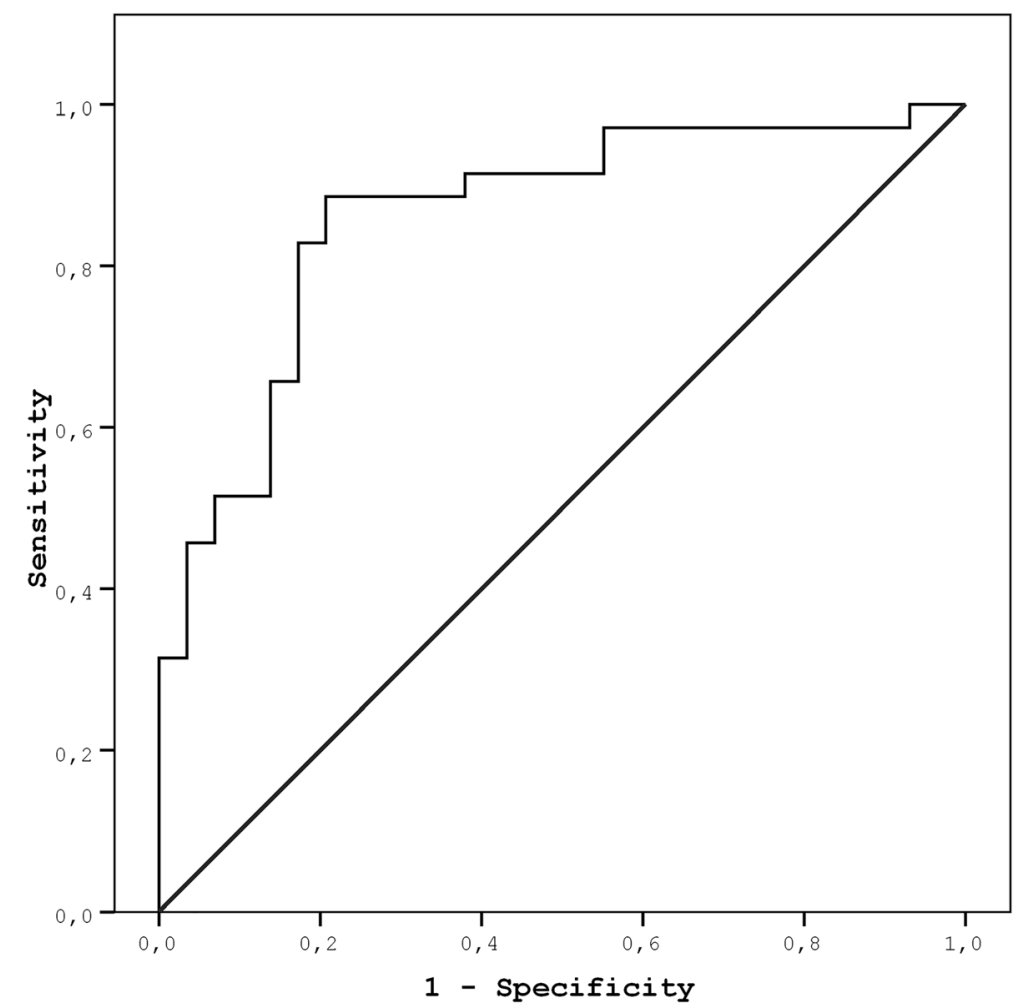

Fig. 2 Receiver-operating characteristic curve of the Monocyte to-HDL-cholesterol ratio for predicting persistent left ventricular systolic dysfunction

of many cardiovascular events. In conjunction with the literature, our results may suggest that inflammation and oxidative stress have a vital role for PPCM pathophysiology and parameters which can directly or indirectly reflect inflammation can play a substantial role in pathophysiology and prognosis of PPCM. In our study, we found that average MHR values of the patients with persistent LV systolic dysfunction were prominently higher than the patients with LV recovery. One may hypothesize that MHR may predict recovery and make clinical decision making easy as to whether a woman with initially low EF may recover. This parameter may be used to establish patients at high risk for adverse outcomes and guiding selection for the type of therapy in patients with PPCM. From a clinical point of view, as a new predictor of inflammation and oxidative stress, special attention should be paid to MHR whenever evaluating a woman with PPCM at initial evaluation.

\section{Limitations}

The most important limitation of the study was its retrospective cross-sectional design. Although a relatively large series of patients with PPCM were examined, the study population was small in size due to the lack of PPCM. Therefore, the small sample size may limit the power of a statistical test in revealing significant predictors. The data were collected from medical records of patients, and different physicians provided the echocardiographic examinationsphysicians. Monocyte and HDL counts were calculated automatically via venous blood samples. Also, prolactin and other other inflammation and oxidation parameters, such as IL-6 and TNF-alpha, were not assessed because they are not usually available in daily practice. Also, this study did not contain a control group. This limitation may lower the power of the study to determine the prediction of the cut-off value for MHR in this specific population. Finally, our study took place in one tertiary center, which may decrease the generalizability of our results.

\section{Conclusion}

Our findings revealed that higher MHR levels were significantly associated with persistent LV systolic dysfunction in PPCM. These results suggest that higher MHR levels may represent a pro-oxidant and pro-inflammatory effect on the myocardium of these patients. As low-cost, simple, reproducible parameters of the $\mathrm{CBC}$ and lipid panel, the MHR can be widely used in clinical practice for prediction of LV recovery. However, our findings should be confirmed in prospective, randomized, large-scale studies involving other inflammatory biomarkers to explain the exact role of MHR in PPCM clearly. 


\section{Abbreviations}

CAD: Coronary artery disease; CAE: Coronary artery ectasia; COPD: Chronic obstructive pulmonary disease; CRP: C-reactive protein; CVD: Cardiovascular disease; DM: Diabetes mellitus; EF: Ejection fraction; HDL: High-density lipoprotein; HT: Hypertension; ICD: Intracardiac defibrillator; LV: Left ventricular; LVEDD: Left ventricular end-diastolic diameter; LVSD: Left ventricular systolic dysfunction; MHR: Monocyte count to high-density lipoprotein cholesterol ratio; OSAS: Obstructive sleep apnea syndrome; PPCM: Peripartum cardiomyopathy; STEMI: ST-segment elevation myocardia infarction; UA: Uric acid

\section{Acknowledgments}

None.

\section{Funding}

No funding was obtained for this study.

\section{Availability of data and materials}

The datasets supporting the conclusions of the study are included in the article. Any additional data will be available on request. Professor Serkan Cay should be contacted to request the data.

\section{Authors' contributions}

FAE conducted the patients' enrolment, data collection, and follow-up work, participated in the data collection and performed the statistical analysis. The author read and approved the final manuscript. SC conducted the patients' enrolment, data collection, and follow-up work, participated in the data collection and performed the statistical analysis. Both authors read and approved the final manuscript.

\section{Ethics approval and consent to participate}

This study was submitted to and approved by the Ethics Commission of Turkiye Yuksek Ihtisas Training and Research Hospital (reference number: E.7411) This is a retrospective study, so the consent to participate is not applicable. Professor Serkan Cay granted administrative permissions to access the raw data.

\section{Consent for publication}

Not applicable.

\section{Competing interests}

The authors declare that they have no competing interests.

\section{Publisher's Note}

Springer Nature remains neutral with regard to jurisdictional claims in published maps and institutional affiliations.

Received: 28 May 2018 Accepted: 7 May 2019

Published online: 15 May 2019

\section{References}

1. Elkayam U. Clinical characteristics of peripartum cardiomyopathy in the United States: diagnosis, prognosis, and management. J Am Coll Cardiol. 2011;58(7):659-70.

2. Sliwa K, Hilfiker-Kleiner D, Petrie MC, Mebazaa A, Pieske B, Buchmann E, Regitz-Zagrosek V, Schaufelberger M, Tavazzi L, van Veldhuisen DJ, et al. Current state of knowledge on aetiology, diagnosis, management, and therapy of peripartum cardiomyopathy: a position statement from the heart failure Association of the European Society of cardiology working group on peripartum cardiomyopathy. Eur J Heart Fail. 2010;12(8):767-78.

3. Brar SS, Khan SS, Sandhu GK, Jorgensen MB, Parikh N, Hsu JW, Shen AY. Incidence, mortality, and racial differences in peripartum cardiomyopathy. Am J Cardiol. 2007;100(2):302-4.

4. Ntusi NB, Mayosi BM. Aetiology and risk factors of peripartum cardiomyopathy: a systematic review. Int J Cardiol. 2009;131(2):168-79.

5. Fett JD, MCTiernan CF. Towards a unifying hypothesis for the pathogenesis of peripartum cardiomyopathy. Int J Cardiol. 2011;153(1):1-3.

6. Biteker M, Kayatas K, Duman D, Turkmen M, Bozkurt B. Peripartum cardiomyopathy: current state of knowledge, new developments and future directions. Curr Cardiol Rev. 2014;10(4):317-26.
7. Dalzell JR, Jackson CE, Gardner RS. An update on peripartum cardiomyopathy. Expert Rev Cardiovasc Ther. 2011;9(9):1155-60

8. Nishimoto O, Matsuda M, Nakamoto K, Nishiyama H, Kuraoka K, Taniyama K, Tamura R, Shimizu W, Kawamoto T. Peripartum cardiomyopathy presenting with syncope due to Torsades de pointes: a case of long QT syndrome with a novel KCNH2 mutation. Intern Med. 2012;51(5):461-4.

9. Karaye KM, Henein MY. Peripartum cardiomyopathy: a review article. Int J Cardiol. 2013;164(1):33-8.

10. Biteker M, Ilhan E, Biteker G, Duman D, Bozkurt B. Delayed recovery in peripartum cardiomyopathy: an indication for long-term follow-up and sustained therapy. Eur J Heart Fail. 2012;14(8):895-901.

11. McNamara DM, Elkayam U, Alharethi R, Damp J, Hsich E, Ewald G, Modi K, Alexis JD, Ramani GV, Semigran MJ, et al. Clinical outcomes for Peripartum cardiomyopathy in North America: results of the IPAC study (investigations of pregnancy-associated cardiomyopathy). J Am Coll Cardiol. 2015;66(8):905-14.

12. Goland S, Modi K, Bitar F, Janmohamed M, Mirocha JM, Czer LS, Illum S, Hatamizadeh P. Elkayam U. Clinical profile and predictors of complications in peripartum cardiomyopathy. J Card Fail. 2009;15(8):645-50.

13. Sliwa K, Skudicky D, Bergemann A, Candy G, Puren A, Sareli P. Peripartum cardiomyopathy: analysis of clinical outcome, left ventricular function, plasma levels of cytokines and Fas/APO-1. J Am Coll Cardiol. 2000;35(3):701-5.

14. Fett JD, Christie LG, Carraway RD, Murphy JG. Five-year prospective study of the incidence and prognosis of peripartum cardiomyopathy at a single institution. Mayo Clin Proc. 2005;80(12):1602-6.

15. Chapa JB, Heiberger HB, Weinert L, Decara J, Lang RM, Hibbard JU. Prognostic value of echocardiography in peripartum cardiomyopathy. Obstet Gynecol. 2005;105(6):1303-8.

16. Blauwet LA, Libhaber E, Forster O, Tibazarwa K, Mebazaa A, Hilfiker-Kleiner $D$, Sliwa K. Predictors of outcome in 176 south African patients with peripartum cardiomyopathy. Heart. 2013;99(5):308-13.

17. Libhaber E, Sliwa K, Bachelier K, Lamont K, Bohm M. Low systolic blood pressure and high resting heart rate as predictors of outcome in patients with peripartum cardiomyopathy. Int J Cardiol. 2015;190:376-82.

18. Hilfiker-Kleiner D, Kaminski K, Podewski E, Bonda T, Schaefer A, Sliwa K, Forster O, Quint A, Landmesser U, Doerries C, et al. A cathepsin D-cleaved $16 \mathrm{kDa}$ form of prolactin mediates postpartum cardiomyopathy. Cell. 2007; 128(3):589-600

19. Sarojini A, Sai Ravi Shanker A, Anitha M. Inflammatory markers-serum level of C-reactive protein, tumor necrotic factor-alpha, and Interleukin-6 as predictors of outcome for Peripartum cardiomyopathy. J Obstet Gynaecol India. 2013;63(4):234-9.

20. Gleicher N, Elkayam U. Peripartum cardiomyopathy, an autoimmune manifestation of allograft rejection? Autoimmun Rev. 2009:8(5):384-7.

21. Sliwa $K$, Forster $\mathrm{O}$, Libhaber E, Fett JD, Sundstrom JB, Hilfiker-Kleiner D, Ansari AA. Peripartum cardiomyopathy: inflammatory markers as predictors of outcome in 100 prospectively studied patients. Eur Heart J. 2006;27(4):441-6.

22. Mann DL. Inflammatory mediators and the failing heart: past, present, and the foreseeable future. Circ Res. 2002;91(11):988-98.

23. Frantz S, Bauersachs J, Ertl G. Post-infarct remodelling: contribution of wound healing and inflammation. Cardiovasc Res. 2009:81(3):474-81.

24. Lambert JM, Lopez EF, Lindsey ML. Macrophage roles following myocardial infarction. Int J Cardiol. 2008;130(2):147-58.

25. Wrigley BJ, Shantsila E, Tapp LD, Lip GY. CD14++CD16+ monocytes in patients with acute ischaemic heart failure. Eur J Clin Investig. 2013;43(2):121-30.

26. Nahrendorf M, Swirski FK, Aikawa E, Stangenberg L, Wurdinger T, Figueiredo $J$, Libby P, Weissleder R, Pittet MJ. The healing myocardium sequentially mobilizes two monocyte subsets with divergent and complementary functions. J Exp Med. 2007;204(12):3037-47.

27. Yvan-Charvet L, Pagler T, Gautier EL, Avagyan S, Siry RL, Han S, Welch CL, Wang N, Randolph GJ, Snoeck HW, et al. ATP-binding cassette transporters and HDL suppress hematopoietic stem cell proliferation. Science. 2010;328(5986):1689-93.

28. Murphy AJ, Woollard KJ. High-density lipoprotein: a potent inhibitor of inflammation. Clin Exp Pharmacol Physiol. 2010;37(7):710-8.

29. Murphy AJ, Chin-Dusting JP, Sviridov D, Woollard KJ. The anti inflammatory effects of high density lipoproteins. Curr Med Chem. 2009;16(6):667-75.

30. Kanbay M, Solak Y, Unal HU, Kurt YG, Gok M, Cetinkaya H, Karaman M, Oguz $\mathrm{Y}$, Eyileten T, Vural A, et al. Monocyte count/HDL cholesterol ratio and cardiovascular events in patients with chronic kidney disease. Int Urol Nephrol. 2014;46(8):1619-25.

31. Karatas MB, Canga Y, Ozcan KS, Ipek G, Gungor B, Onuk T, Durmus G, Oz A, Karaca M, Bolca O. Monocyte to high-density lipoprotein ratio as a new 
prognostic marker in patients with STEMI undergoing primary percutaneous coronary intervention. Am J Emerg Med. 2016;34(2):240-4.

32. Yilmaz S, Akboga MK, Sen F, Balci KG, Aras D, Temizhan A, Aydogdu S.

Usefulness of the monocyte-to-high-density lipoprotein cholesterol ratio to predict bare metal stent restenosis. Biomark Med. 2016;10(9):959-66.

33. Ucar FM. A potential marker of bare metal stent restenosis: monocyte count - to- HDL cholesterol ratio. BMC Cardiovasc Disord. 2016;16(1):186.

34. Kundi H, Gok M, Kiziltunc E, Cetin M, Cicekcioglu H, Cetin ZG, Karayigit O, Ornek E. Relation between monocyte to high-density lipoprotein cholesterol ratio with presence and severity of isolated coronary artery ectasia. Am J Cardiol. 2015;116(11):1685-9.

35. Inonu Koseoglu H, Pazarli AC, Kanbay A, Demir O. Monocyte count/HDL cholesterol ratio and cardiovascular disease in patients with obstructive sleep apnea syndrome: a multicenter study. Clin Appl Thromb/Hemost. 2018;24(1):139-44

Ready to submit your research? Choose BMC and benefit from:

- fast, convenient online submission

- thorough peer review by experienced researchers in your field

- rapid publication on acceptance

- support for research data, including large and complex data types

- gold Open Access which fosters wider collaboration and increased citations

- maximum visibility for your research: over $100 \mathrm{M}$ website views per year

At $\mathrm{BMC}$, research is always in progress.

Learn more biomedcentral.com/submissions 